\title{
Fathers and Families: Risk and Resilience. An Introduction
}

\author{
Hiram E. Fitzgerald ${ }^{1,2} \cdot$ Lara R. Robinson $^{3} \cdot$ Natasha Cabrera $^{4} \cdot$ Leonie Segal $^{5}$
}

Accepted: 16 May 2021 / Published online: 25 June 2021

(c) Springer Nature Switzerland AG 2021

\begin{abstract}
The articles in this special issue are informed by the historic changes in the twentieth century (i.e., decreasing family size, changing family roles, and youth demonstrating more independent behaviors) that propelled intensive study of fathers' impacts on child development. The papers are conceptualized within a developmental systems framework and focused on a father's presence rather than on his absence in the family, going beyond the study of merely father involvement. Papers reflect longitudinal and cross-sectional methods and examine issues related to paternal mental health, parenting behavior, cultural context, and children's physical and mental health.
\end{abstract}

Keywords Fathers · Systems $\cdot$ Longitudinal studies $\cdot$ Risk $\cdot$ Resilience $\cdot$ Maternal essentialism $\cdot$ Parenting stress $\cdot$ Expectant fathers $\cdot$ Familism $\cdot$ Paternal alcoholism $\cdot$ Parental mental health problems $\cdot$ Paternal resilience

In 1926, Ernest Burgess responded to changes taking place in the American family of that time (i.e., decreasing family size, changing family roles, and youth demonstrating more independent behaviors) by describing the family as an interactional system, a composite or unity of interacting personalities (Loukas et al., 1998). Although he did not provide in-depth commentary on the role of the father, he set

Hiram E. Fitzgerald

fitzger9@msu.edu

Lara R. Robinson

lpr0@cdc.gov

Natasha Cabrera

ncabrera@umd.edu

Leonie Segal

Leonie.Segal@unisa.edu

1 Department of Psychology, Michigan State University, East Lansing, MI 48824, USA

2 BankWest Economics Research Center, Curtin University, Bentley, WA 6102, Australia

3 National Center On Birth Defects and Developmental Disabilities, Centers for Disease Control and Prevention, Atlanta, GA 30341, USA

4 Department of Human Development and Quantitative Methodology, University of Maryland, College Park, MD 20742, USA

5 Health Economics and Social Policy, Australian Centre for Precision Health, Allied Health and Human Movement, University of South Australia, Adelaide, SA 5001, Australia the stage for the emergence of systems concepts of family life (Bowen, 1971; Minuchin, 1974) and the importance of interpersonal relationships in family dynamics. Four decades later, Nash (1965) noted that fathers were a neglected aspect of research in human development potentially distorting a deeper understanding of the dynamics of child development. Researchers responded to Nash's concern over a lack of fatherhood research (Parke \& Sawin, 1976; Parke, \& O'Leary, 1976) with special attention to the father's role in child development (Lamb, 1976, 1987; Lamb et al., 1987; Palkovitz, 2002).

By the end of the century, thousands of studies were published (Lewis, 2012) with articles assessing the impact of fathers on a wide range of issues related to child development (Bocknek et al., 2014; Boller \& Bradley, 2006; Cabrera et al., 2007a; Fitzgerald \& Bradley, 2012; Fitzgerald \& McGreal, 1981; Roggman \& Cabrera, 2011; Volling \& Cabrera 2019). Indeed, in response to the volume of research in the context of continued speculation about the importance of father-child relationships, Lewis (2012) asked, "Why do we know so little about fathers, when there is so much research on them?" (p. 229). Mackey (1996) suggested that many studies of fathers are driven by theories originally developed to guide research on mother-infant relationships. He noted "...the father was not selected to be a mother. He is different. Whereas the mother is an infant specialist, he is not. He is a toddler and beyond specialist in the domain of rough-and-tumble play and exploring the environment" 
(p. 91.), presaging von Klitzing's (2011) observation that "fathers have to be different from mothers to help children orient themselves in multidimensional space" (p. 157). The new research interest in fathers arose at the same time as the shift away from mechanistic views of human development (i.e., that the individual is reactive to events in the world) to a view of the individual as an active agent interacting and responding to environmental changes and shifts within contexts across time, representative of more organismic, biopsychosocial, and dynamic views of human development. Organismic theories were heavily influenced by general systems theory (GST) (Bertalanffy, 1968; Lazlo, 1972; Levine \& Fitzgerald, 1992; Sameroff, 1995, 2010), and by variants of GST such as bioecological (Bronfenbrenner \& Morris, 2006), relational-developmental (Overton, 2013, 2015), dynamic (Ford \& Lerner, 1992; Whitherington, 2015), and transactional (Sameroff, 2003) models. These theories shared a view of human development as transactional and influenced by the intersection of genetic, epigenetic, and lived experience over the life course.

Despite the volumes of research on fathers, no dominant theory arose to drive research in the way that Bowlby's (1973) theory of attachment drove research with mothers and their young children. Paternal research focused on a multidimensional concept called "father involvement" (Tamis-LeMonda \& Cabrera, 2002; Cabrera \& TamisLaMonda, 2013). Cabrera et al. (2007a, 2014) developed a conceptual model to guide research on fathers, analogous to the heuristic model Garcia Coll and colleagues (Garcia Coll et al., 1996) offered to guide research on children from minority groups and their families. Caberera and colleagues' model (Cabrera et al., 2007b, 2014) was designed to accomplish four goals with respect to research on fathers and child development (p. 348):

1. Organize systematically the study of fathers in relation to their children's well-being and development within a transactional dynamic system framework.

2. Consider the factors that affect fathers' involvement with their children.

3. Consider the factors that mediate or moderate the pathways from father involvement to child outcomes; and

4. Consider fathers' characteristics and parenting as mediators and moderators of other influences on their children's development.

The articles in this special issue of Adversity and Resilience Science: Journal of Research and Practice are informed by the Cabrera et al. (2014) model and by the Risk to Resilience Continuum (Fitzgerald, 2010, Fitzgerald et al., 2020). We conceptualize the child's environment as a multidimensional space (e.g., von Klitzing, 2011) in which parenting influences children systemically, thus including fathers, father-mother relationships, gene-environment interplay, co-parenting, and adjunctive influences external to the family because few, if any, children are raised exclusively in dyadic, parent-child relationships (Emde, 1991; Fivaz-Depeursinge \& Corboz-Warnery, 1999). Furthermore, as children traverse the life course, their multidimensional space increasingly expands beyond the confines of family, challenging unidirectional models of child development. A shift to interactional models may be better representations of actual lived experience (Cabrera et al., 2014).

Three articles in this special issue include data from mothers and fathers (Cabrera et al., 2021; Mendonca et al., 2021; Wolicki et al., 2021) and two focus on data from fathers (Eiden \& Livingston, 2021; Schoppe-Sullivan et al., 2021). With respect to methods, four use data from on-going longitudinal studies (Cabrera et al., 2021; Eiden \& Livingston, 2021; Mendonca et al. 2021; Schoppe-Sullivan et al., 2021), and one combines multiple years of a national representative cross-sectional sample (Wolicki et al., 2021); of these studies, two focus on fathers from low-income communities (Cabrera et al, 2021; Mendonca, et al, 2021). The final article in this special issue is a commentary (Palkovitz \& Fagan, 2021). The common factor across all studies in this special issue is a focus on fathers' direct and indirect influences on child development, within the context of a family system.

As noted earlier, research with fathers and infants began in earnest during the 1970s and has continued to date. Nevertheless, studies of mother-infant and young children's development continued to dominate the literature, particularly with respect to issues related to social-emotional development (NASEM, 2016). Within the maternally focused parenting literature, one lane of research has examined the extent to which the parents' own childhood, and especially earlier exposure to adversities, may negatively affect their parenting practices, primarily through unconscious processes (Amos et al., 2015). Freiberg referred to such past experiences as "ghosts in the nursery" (Fraiberg et al., 1975). More recently, Lieberman and colleagues provide evidence that positive events in parents' own childhoods also transfer intergenerationally, referring to such benevolent experiences metaphorically as "angels" (Lieberman et al., 2005). Using measures of benevolent childhood experiences (BCE) and adverse childhood experiences (ACE), Narayan et al. (2020) found evidence for direct effects of ACES (ghosts) on mothers' childhood memories from the prenatal period to 3-4 months postnatally, but for BCE postnatal effects were mediated by prenatal memories. Barrows (2004) has provided convincing arguments that fathers' memories of their childhood (ghosts) affect prospective male parents, but studies of angel memories in fathers' pasts have yet to be undertaken. 
Bretherton et al. (2006) drew attention to the intergenerational transmission of men's parenting representations based on their own fathers' parenting practices. One example of which is found in intergenerational studies of paternal alcoholism and antisocial behavior (Fuller et al., 2003). Skjothaug and colleagues (Skjothaug et al., 2015, 2018) similarly documented that many prospective first-time fathers experience anxiety and stress during pregnancy (sometimes referred to as couvade syndrome; Trethowan \& Conlon, $1965)$ that can be exacerbated due to adverse experiences in their own childhood, especially in relation to their own fathers' parenting behavior or lack thereof.

In addition to being influenced by a father's history, new parenting experiences are influenced by the dynamics in the marital relationship. Mackey (1996) found in studies of the American father that fathers were positively influenced about their parenting behavior when their spouse encouraged them to participate in the parenting process (in contrast to isolating them from caregiving responsibilities). The related question that Schoppe-Sullivan et al. (this issue, 2021) raised is as follows: What are the predictors of parenting stress and satisfaction of new fathers? Data from their study indicate that fathers' higher prenatal anxiety predicted higher postnatal parenting stress levels; fathers' prenatal anxiety and postnatal parenting stress were both positively associated with infant negative emotionality (i.e., signs of distress, crying). These results affirm Skjothaug et al.'s $(2015,2018)$ call to include assessments of fathers' mental health as well as that of mothers in studies of children's antenatal, perinatal, and postnatal development. Schopp-Sullivan and colleagues (Schoppe-Sullivan et al., 2021) also found that fathers who more strongly believed prenatally in maternal essentialism (pre-existing beliefs related to maternal biological preparedness for parenting) had higher levels of postnatal parenting stress regardless of infant negative emotionality. In addition, the role of mothers' responses to the fathering role was documented. Maternal postnatal encouragement of the fathers' parenting was associated with lower postnatal paternal stress, lower infant negative emotionality, and higher parenting satisfaction among fathers. In contrast, maternal gate-closing (i.e., criticism and discouraging behaviors when a father did something with his child that the mother disagreed with) was associated with higher postnatal paternal stress. Mothers may thus have considerable influence over the quality of the father-child relationship.

One way parents can stimulate optimal development is to read books to infants and very young children. Most studies of book reading focus on mothers and their children. Some studies suggest that when fathers read to their very young children, they talk more, use a more diverse vocabulary, and ask their toddlers many more questions than do mothers (Duursma et al., 2020; Schwab et al., 2018). Drawing on data from their Baby Books Project, Cabrera et al., (this issue,
2021) explored whether diverse talking during book reading with 9-month-olds (e.g., asking lots of questions, adding to the story, or embellishing it) was associated with children's social development (defined as levels of positive behavior and social skills at 30 months). They report that maternal distress during book reading, but not father distress, was negatively related to toddlers' positive social skills. Maternal nurturance during book reading, but not paternal nurturance, was correlated with low levels of toddlers' behavior problems and high social skills. Although fathers' book reading may positively affect toddlers' language development, future research could explore if a different kind of parenting interaction is needed to evoke an impact on toddlers' selfregulatory competence or resilience building.

Another factor that can influence parental involvement with infants and very young children is the cultural context into which they are born (Shwalb et al., 2013). In some cases, parental cultural context is shared (i.e., both parents share the same ethnicity) but in other cases, parents have unique ethnic beliefs and traditions that they blend into a multicultural context for their children (Fitzgerald et al., 2009, 2010). Mendonca et al., (this issue, 2021) report findings from their studies of parents from low-income households in Brazil. Their primary question of interest concerned the extent to which parents' socialization goals and familism (i.e., beliefs that individual interests are subordinate to the family; Delgado et al., 2020) affected interactional synchrony with their toddlers during a free-play task. Maternal and paternal cultural variables were distinctly associated with interactional synchrony; greater variation in interactional synchrony occurred within father-infant than within mother-infant interaction groups. The authors suggest that Brazilian fathers may be influenced more strongly by traditional cultural orientations than are mothers.

Another context where fathers are found to have a more profound effect on child and family life involves individual and family substance abuse and associated paternal psychopathology, particularly paternal antisocial behavior. Longitudinal studies of families with high paternal psychopathology indicate that by age five, children in these families have a greater likelihood of high levels of externalizing and internalizing behavior, difficult temperaments, insecure attachments, and difficulties with emotional and behavioral self-regulation (Eiden et al., 1999; Fitzgerald et al., 2007). Moreover, there is increasing evidence that aggression and violence among males can be transmitted intergenerationally (Fuller et al., 2003; Snarey, 1993). Despite early adversity, however, other life course experiences can change children's experiential worlds exposing them to environments that support resiliency skills that not only affect them psychologically, but also affect their neurobiological systems and buffer many of the effects of early exposure to parental psychopathology (Fitzgerald \& Puttler, 2019; Zucker et al., 2003). 
Eiden and Livingston (this issue, 2021) report on their longitudinal study that illustrates the complexity of life course impacts of paternal alcoholism and co-related psychopathology on children's peer victimization behaviors (i.e., in-person and cyber victimization) through adolescence. They report evidence supporting two pathways in which paternal alcoholism, intimate partner violence, and depression in early and middle childhood had differential associations with their sons' physical/in-person bullying victimization and cyber victimization during late adolescence. Through different pathways, fathers' sensitivity with their sons in middle childhood also predicted children's lower levels of cyber victimization but, unexpectedly, was associated with higher levels of in-person victimization and cyber victimization in-directly through child emotion regulation skills.

Using nationally representative cross-sectional data from 3 years of the National Survey of Children's Health, Wolicki and colleagues (Wolicki et al., this issue, 2021) examined the relationship between parents' and primary caregivers' self-reported mental and physical health and primary caregiver report of diagnosed child mental disorders and child general physical health. They report data on both male and female primary caregivers and male and female children ( $0-17$ years old). Related to findings reported by Eiden and Livingston (this issue, 2021), Wolicki and colleagues report that children with male primary caregivers with poor mental health were more likely to have poor general health, one or more mental, behavioral, or developmental disorders, two or more adverse childhood experiences (e.g., exposure to violence or family disruptions such as divorce), and to be living in poverty, when compared to children of male primary caregivers with good mental health. Of note, these analyses seek to address a gap in the research on the impact of male caregiver mental health on child outcomes by using nationally representative data.

Findings from the papers in this special issue provide support of the broader literature indicating the negative impacts of paternal substance abuse, antisocial behavior, depression, anxiety, and stress on child development. However, family dynamics involve relationships that extend far beyond dyadic and triadic interactions. Family members are embedded in and influenced by a broad range of additional external system influences that often exacerbate family troubles (Fitzgerald et al., 2010; Fitzgerald \& Puttler, 2018; Fitzgerald et al., 2019), but also can provide resilience building experiences as well (Ferguson \& Horwood, 2003).

In the final article, Palkovitz and Fagan (this issue, 2021) draw attention to the impact of the global COVID-19 pandemic on fathers and their families. The pandemic virus has impacted families throughout the world but with a particularly high burden with respect to infection rates and deaths in the USA, especially exacerbating vulnerabilities among children and families already marginalized due to historic, structural, and race-based discrimination and oppression (Fraiman et al., 2021; Yip, 2020). Palkovitz and Fagan's commentary stresses the interdependence of family members across the intersection of race, class, culture, and individual characteristics, with the additional interconnectivity with community adjunctive systems as they systemically impact risk and resilience within family dynamics. They draw attention to the resource theory of fathering (Palkovitz \& Hull, 2018) as one way to conceptualize and study fathers' role relationships within the context of biopsychosocial, spiritual, and differential resources available to them, and their ability to manage such resources within the context of the COVID-19 pandemic.

The study of father influences on child development, sparked by John Nash 44 years ago, has generated a large and somewhat disperse literature, much of which is concerned with the concept of "involvement," and is linked loosely to the heuristic model proposed by Cabrera et al. (2014). In addition, fatherhood research has expanded beyond the borders of Western countries and cultures adding important information to the diversity of human development. While investigators have used multiple methods, diverse research designs, and conceptual frameworks, one thing is noticeably absent from all of these scientific studies of fathers and child development, namely, the voices of children. Children are dynamic players in the family environment and form mental representations, expectancies, and beliefs from their interactions with parents that become embedded in their concepts of self, others, and self-other relationships (Fitzgerald et al., 2019). If we want to have a complete understanding of the importance of fathers in or out of the lives of children, we could consider adding the narrative voices of children to our efforts to discover how and under what circumstances fathers matter to them from their point of view!

In summary, the articles in this special issue describe fatherhood from a dynamic, transactional perspective, illustrating how fathers within the family context indirectly and directly impact child development. Spanning in development from the transition to fatherhood to parenting an adolescent and across sociodemographic and economic groups, the articles suggest that attention should be paid to risk and resilience factors within the entire family unit. Several of the studies highlight the impacts of paternal psychopathology and stress on poor child outcomes (e.g., infant distress and mental disorders) while others identified resiliency factors (e.g., paternal sensitivity, cultural beliefs, and maternal supportive behaviors) that promote positive father-child interactions and child development. Overall, these studies examine the complexities and resources within the family going beyond the concept of father involvement. As such, this deeper dive into the study of fathers provides research to begin to address a gap (NASEM, 2016) in both the evidence 
on the importance of the father-child relationship and parenting supports that nurture the strengths of that relationship.

Funding During preparation of this paper, Dr. Cabrera was supported, in part, by the National Institute of Child Health and Human Development (R01HD078547) in the National Institutes of Health, USA, Department of Health and Human Services.

\section{Declarations}

Conflict of Interest The authors declare no competing interests.

Disclaimer The findings and conclusions in this article are those of the authors and do not necessarily represent the official position of the Centers for Disease Control and Prevention.

\section{References}

Amos, J., Segal, L., \& Cantor, C. (2015). Entrapped mother, entrapped child: Agonic mode, hierarchy and appeasement in intergenerational abuse and neglect. Journal of Child and Family Studies, 24, 1442-1450.

Barrows, P. (2004). Fathers and families: Locating the ghosts in the nursery. Infant Mental Health Journal, 25, 408-428.

Bocknek, E. L., Hossain, Z., \& Roggman, L. (Eds) (2014). Very young children and their fathers [Special Issue]. Infant Mental Health Journal, 35, 389-526.

Boller, K., \& Bradley, R. (Eds) (2006). Early head start fathers and children. [Special Issue]. Parenting: Science and Practice. 6(2-3), 117-272.

Bowlby, J. (1973). Attachment and loss: Vol. II: Separation, anxiety and anger. Basic Books.

Bowen, M. (1971). Family therapy and family group therapy. In H. Kaplan \& B. Sadok (Eds.), Comprehensive group psychotherapy (pp. 384-421). Williams \& Wilkins.

Bretherton, I., Lambert, J. D., \& Gelby, B. (2006). Modeling and reworking childhood experiences: Involved fathers' representations of being parented and of parenting a preschool child. In O. Mayseless (Ed.), Parenting representations: Theory, research, and clinical implications (pp. 177-207). Cambridge University Press.

Bronfenbrenner, U., \& Morris, P. A.(2006). The bioecological model of human development. In P. Mussen (Ed). Handbook of child psychology. Wiley.

Burgess, E. W. (1926). The family as a unity of interacting personalities. The Family, 7(1), 3-9.

Cabrera, N., J., Fitzgerald, H. E., Bradley, R. H., \& Roggman, L. (2007a). Modeling the dynamics of paternal influences on children over the life course. Applied Developmental Science, 11, 185-190.

Cabrera, N. J., Fitzgerald, H. E., \& Shannon, J. (Eds). (2007b). Fatherhood: Understanding the impact of fathers on child development. [Special Issue]. Applied Developmental Science, 11, 185-272.

Cabrera, N. J., Fitzgerald, H. E., Bradley, R. H., \& Roggman, L. (2014). The ecology of father-child relationships: An expanded model. Journal of Family Theory and Review, 6, 336-354.

Cabrera, N., Hennigar, A., Alonso, A., McDorman, S. A., \& Reich,S. (2021). Maternal and paternal protective factors, resilience, environmental risk, and children's positive social development.Adversity and Resilience Science: Journal of Research and Practice. 2, 000-000.
Cabrera, N. J., \& Tamis-LaMonda, C. W. (2013). Handbook of father involvement: Multidisciplinary perspectives (2nd ed.). Routledge.

Delgado, M. Y., Nair, R. L., Zeiders, K. H., \& Jones, S. K. (2020). Latino adolescents' experiences with ethnic discrimination: Moderating factors and mediating mechanisms. In H. E. Fitzgerald, D. J. Johnson, D. B. Qin, F. A. Villarruel, \& J. Norder (Eds.). Handbook of children and prejudice: Integrating research, practice and policy (pp 515-531). Springer Nature.

Duursma, E., Ho, C. J., Townsend, M. L., Grenyer, B. F., Herbert, J. E. (2020). Fathers talking and reading with their 3-year-olds during shared bookreading. In H. E. Fitzgerald, von Klitzing, K., Cabrera, N.J., de Mendonca, J. S., \& Skjothaug, T. (Eds). Handbook of fathers and child development: Prenatal to preschool (pp 411-33). Springer Nature

Eiden, R. D., \& Livingston, J.A., (2021). Risk and protective pathways to peer victimization from infancy to adolescence: Role of fathers. Adversity and Resilience Science: Journal of Research and Practice, 2, 000-000.

Eiden, R. D., Chavez, F., \& Leonard, K. E. (1999). Parent-infant interactions among families with + alcoholic fathers. Development and Psychopathology, 11, 745-762.

Emde, R. N. (1991). The wonder of our complex enterprise: Steps enable by attachment and the effects of relationships on relationships. Infant Mental Health Journal, 12, 165-173.

Ferguson, D. M., \& Horwood, L. J. (2003). Resilience to childhood adversity: Results of a 21-year study. In S. S. Luthar (Ed.), Resilience and vulnerability: Adaptation in the context of childhood adversities (pp. 130-155). Cambridge University Press.

Fitzgerald, H. E. (2010). A community driven framework for systems change. The Engaged Scholar, 5, 20-21.

Fitzgerald, H. E., \& Bradley, R. (Eds) (2012). Paternal family relationships, child risk, and child outcomes. [Special Issue]. Family Science, 3 (3-4), 141-236.

Fitzgerald, H.E., Johnson, D. J., Qin, D. B., Villarruel, F. A., \& Norder, J. (2019). Introduction: A developmental systems perspective on children and prejudice. In H. E. Fitzgerald, D. J. Johnson, D. B. Qin, F. A. Villarruel, \& J. Norder (Eds). Handbook of children and prejudice: Integrating research, practice and policy (pps 3-22). Springer Nature.

Fitzgerald, H. E., Klitzing, K. von, Cabrera, N. J., de Mendonca, J. S., \& Skjothaug, T. (2020). Fathers and very young children: A developmental systems perspective. In H. E. Fitzgerald, K. von Klitzing, N. J. Cabrera, J.S. de Mendonca, \& T,. Skojthaug (Eds,). Handbook of fathers and child development: Prenatal to preschool (pps 5-28). Springer Nature.

Fitzgerald, H. E., \& Puttler, L. I. (Eds.). (2019). Alcohol use disorders: A developmental science approach to etiology. Oxford University Press.

Fitzgerald, H. E., Puttler, L. I., Refior, S., \& Zucker, R. A. (2007). Family responses to children and alcohol. Alcoholism Treatment Quarterly: Families and Alcoholism, 25, 11-25.

Fitzgerald, H. E., Mann, T., Cabrera, N., Sarche, M., \& Qin, D. (2009). Infants and toddlers in ethnoracial families. Infant Mental Health Journal, 30, 425-432.

Fitzgerald, H. E., Mann, T., Cabrera, N., Sarche, M., \& Qin, D. (2010). Tidlig barndom og identitet I multikulturelle miljoe (Infancy and identity in cultural context). In V. Moe, K. Slinning, \& M. B. Hansen (Eds). Handbook of infant and toddler psychology (pp 269-282). Gyldendal Akademisk.

Fitzgerald, H. E., \& McGreal, C. E. (Eds). (1981). Fathers and infants. [Special Issue]. Infant Mental Health Journal, 2(4), 213-294.

Fivaz-Depeursinge, E., \& Corboz-Warnery, A. (1999). The primary triangle: A developmental systems view of mother, fathers, and infants. Basic Books.

Ford, D. H., \& Lerner, R. M. (1992). Developmental systems theory: An integrative approach. Sage. 
Fraiberg, S., Adelson, E., \& Shapiro, V. (1975). Ghosts in the nursery: A psychoanalytic approach to the problems of impaired infantmother relationships. Journal of the American Academy of Child Psychiatry, 14, 387-421.

Fraiman, Y. S., Litt, J. S., Davis, J. M., \& the Pediatric Policy Council, . (2021). Racial and ethnic disparities in adult COVID-19 and the future impact on child health. Pediatric Research. https://doi.org/ 10.1038/s41390-021-01377-x

Fuller, B. E., Chermack, S. T., Cruise, K. A., Kirsch, E., Fitzgerald, H. E., \& Zucker, R. A. (2003). Predictors of childhood aggression across three generations in children of alcoholics: Relationships involving parental alcoholism, individual and spousal aggression, and parenting practices. Journal of Studies on Alcohol, 64, 472-483.

Garcia Coll, C., Lamberty, G., Jenkins, R., McAdoo, H. P., Crnic, K., Wasik, B. H., \& Garcia, h. W. (1996). An integrative model for the study of developmental competencies in minority children. Child Development, 67, 1891-1914.

Lamb, M. E. (Ed.). (1976). The role of the father in child development. Wiley.

Lamb, M. E. (Ed.). (1987). The fathers' role: cross cultural perspectives. Routledge.

Lamb, M. E., Pleck, J. H., Charnov, E. L., \& Levine, J. A. (1987). A biosocial perspective on paternal behavior and involvement. In J. B. Lancaster, J. Altmann, A. S. Rossi, \& L. R. Sherrod (Eds.), Parenting across the lifespan: Biosocial dimensions (pp. 111-142). Aldine de Gruyter.

Lazlo, E. (1972). Introduction to systems philosophy: Toward a new paradigm of contemporary thought. Harper \& Row.

Levine, R. L., \& Fitzgerald, H. E. (Eds). (1992). Analysis of dynamic psychological systems: Vol. 1. Basic approaches to general systems, dynamic systems, and cybernetics. Plenum Press.

Lewis, C. (2012). Commentary: What are the links between fathering, family relationships, risk and child outcomes? Methodological and Theoretical Issues. Family Science, 3(3-4), 229-232.

Lieberman, A. F., Padron, E., Van Horn, P., \& Harris, W. W. (2005). Angels in the nursery: The intergenerational transmission of benevolent parental influences. Infant Mental Health Journal., 26, 504-520.

Loukas, A., Twitchell, G. R., Piejak, L. A., Fitzgerald, H. E., \& Zucker, R. A. (1998). The family as a unity of interacting personalities. In L. L'Abate (Ed.), Handbook of family psychopathology (pp. 35-59). Guilford Publications.

Mackey, W. C., (1996). The American father: Biocultural and developmental aspects. Plenum Press.

Mendonca, J. S. de, Felipe, R. P. de, \& David, V. F. (2021). Socialization goals, familism and interactional synchrony in low-income Brazilian mothers and fathers. Adversity and Resilience Science: Journal of Research and Practice, 2, 000-000.

Minuchin, S. (1974). Families and family therapy. Harvard University Press.

Narayan, A. J., Atzl, V. M., Merrick, J. S., Harris, W. W., \& Lieberman, A. F. (2020). Developmental origins of ghosts and angels in the nursery: Adverse and benevolent childhood experiences. Adversity and Resilience Science, 1, 121-134.

Nash, J. (1965). The father in contemporary culture and current psychological literature. Child Development, 36, 261-297.

National Academies of Sciences, Engineering, and Medicine (2016). Parenting matters: Supporting parents of children ages $0-8$. The National Academies Press.

Overton, W. F. (2013). A new paradigm for developmental science: Relationism and relational-developmental systems. Applied Developmental Science, 17, 94-107.

Overton, W. F. (2015). Processes, relations, and relational-developmental-systems. In W., F. Overton \& P, C. M. Molenaar (Eds).
Handbook of child psychology and developmental science Vol 1: Theory and method (pp 9-69). Wiley

Palkovitz, R. (2002). Involved fathering and child development: Advancing our understanding of good fathering. In C. S. TamisLeMonda \& N. Cabrera (Eds.), Handbook of father involvement (pp. 33-64). Lawrence Erlbaum.

Palkovitz, R., \& Fagan, J. (2021). Faces of risk and resilience: Fathers and their families. Adversity and Resilience Science: Journal of Research and Practice. 2, 000-000.

Palkovitz, R. \& Hull, J. (2018). Toward a resource theory of fathering. Journal of Family Theory and Review, 10, 181-198.

Paquette, D. (2004). Theorizing the father-child relationship: Mechanisms and developmental outcomes. Human Development, 47, 193-219.

Parke, R.D. \& O'Leary, S. E. (1976). Father-mother-infant interaction in the newborn period: Some findings, some observations and some unresolved issues. In K. Riegel \& J. Meacham (Eds). The developing individual in a changing world. Vol. 2: Social and environmental issues. Mouton.

Parke, R. D., \& Sawin, D. B. (1976). The father's role in infancy: A re-evaluation. The Family Coordinator, 25, 365-371.

Roggman, L. \& Cabrera, N. (2011). Fathers engagement and children's outcomes in a at-risk populations. [Special Issue]. Family Science, 2(2):73-75.

Sameroff, A. J. (1995). General systems theories and developmental psychopathology. In D. Cicchetti \& D.J. Cohen (Eds). Developmental psychopathology Vol 1: Theory and methods (pp 659-695). Wiley.

Sameroff, A. J. (2003). Developmental systems: Contexts and evolution. In W. Kessen * P. H. Mussen (Eds). Handbook of child psychology $\left(4^{\text {th }}\right.$ Ed), Vol 1: History, theory, and methods (pp 237-294). Wiley.

Sameroff, A. (2010). A unified theory of development: A dialectical integration of nature and nurture. Child Development, 81(1), 6-22.

Schoppe-Sullivan, S., Donithen, R. W., Lee, J-0K., Simon, L. T., \& Wang, J. (2021). The best and worst of times: Predictors of new fathers' parenting satisfaction and stress. Adversity and Resilience Science: Journal of Research and Practice., 2, 000-000.

Schwab, J. E., Rowe, W. L., Cabrera, N., \& Lew-Williams, C. (2018). Fathers' repetition of words is coupled with children's vocabularies. Journal of Experimental Child Psychology, 166, 437-450.

Shwalb, D. W., Shwalb, B. J., \& Lamb, M. E. (2013). Fathers in cultural context. Routledge.

Skjothaug, T., Smith, L., Wentzel-Larsen, T., \& Moe, V. (2015). Prospective fathers' adverse childhood experiences, pregnancyrelated anxiety, and depression during pregnancy. InFant Mental Health Journal, 36, 104-113.

Skjothaug, T., Smith, L., Wentzel-Larsen, T., \& Moe, V. (2018). Does fathers' prenatal mental health bear a relationship to parenting stress at 6 months? Infant Mental Health Journal, 39, 537-551.

Snarey, J. (1993). How fathers care for the next generation: A fourdecade study. Harvard University Press.

Tamis-LeMonda, C. W., \& Cabrera, N. J. (2002). Handbook of father involvement: Multidisciplinary perspectives. Erlbaum.

Trethowan, W. H., \& Conlon, M. F. (1965). The couvade syndrome. British Journal of Psychiatry, 111, 57-65.

Volling, B.L., \& Cabrera, N. J. (Eds). (2019). Advancing research and measurement on fathering and children's development. Monographs of the Society for Research on Child Development, Serial No. 332,84 , No. 1

von Bertalanffy, L. (1968). General systems theory. George Braziller.

Von Klitzing, K. (2011). Commentary on the special issue. Family Science, 2, 156-158.

Whitherington, D. C. (2015). Dynamic systems in developmental science. In W., F. Overton \& P, C. M. Molenaar (Eds). Handbook of 
child psychology and developmental science Vol 1: Theory and method (pp 63-112). Wiley

Wolicki, S.B., Bitsko, R.H., Cree, R. A., Danielson, M. L., Ko,J., Warner, Lee, \& Robinson, L.R (2021). Mental health of parents and primary caregivers by sex and associated child health indicators. Adversity and Resilience Science: Journal of Research and Practice, 2, 000-000.

Yip, T. (Ed.) (2020). Addressing inequities in education during the COVID-19 pandemic: How education policy and schools can support historically and currently marginalized children and youth. Society for Research in Child Development Statement of the Evidence. Washington, DC.

Zucker, R. A., Wong, M. M., Puttler, L. I., \& Fitzgerald, H. E. (2003). Resilience and vulnerability among sons of alcoholics. In S. S. Luthar (Ed.), Resilience and vulnerability: Adaptation in the context of childhood adversities (pp. 76-103). Cambridge University Press. 